\title{
Group Decision-Making from an Evolutionary/Adaptationist Perspective
}

\author{
R. Scott Tindale \\ Loyola University Chicago, rtindal@luc.edu \\ Tatsuya Kameda \\ University of Tokyo
}

Follow this and additional works at: https://ecommons.luc.edu/psychology_facpubs

Part of the Social Psychology Commons

Author Manuscript

This is a pre-publication author manuscript of the final, published article.

\section{Recommended Citation}

Tindale, R. Scott and Kameda, Tatsuya. Group Decision-Making from an Evolutionary/Adaptationist Perspective. Group Processes and Intergroup Relations, 20, 5: 669-680, 2017. Retrieved from Loyola eCommons, Psychology: Faculty Publications and Other Works, http://dx.doi.org/10.1177/ 1368430217708863

This Article is brought to you for free and open access by the Faculty Publications and Other Works by Department at Loyola eCommons. It has been accepted for inclusion in Psychology: Faculty Publications and Other Works by an authorized administrator of Loyola eCommons. For more information, please contact ecommons@luc.edu. cc) (i) $\ominus$

This work is licensed under a Creative Commons Attribution-Noncommercial-No Derivative Works 3.0 License. (C) The Authors 2017 
Group Decision Making from an Evolutionary/Adaptationist Perspective

R. Scott Tindale

Tatsuya Kameda

Loyola University Chicago

University of Tokyo

Correspondence should be sent to R. Scott Tindale, Department of Psychology, Loyola University Chicago, 1032 W. Sheridan Rd., Chicago, IL 60660 - $\underline{\text { rtindal@ luc.edu }}$ 


\begin{abstract}
Over the 20 years that Group Processes and Intergroup Relations has been in existence, evolutionary theory has begun to play a larger role in our understanding of human social behavior. Theory and research on group decision-making is no exception and the present paper attempts to briefly highlight how an evolutionary/adaptationist perspective has informed our understanding of how groups reach consensus and make collective choices. In addition, we attempt to show that humans are not the only species that use group processes to make important choices. Looking for similarities and continuities among research domains with different species should lead to a more unified and informed understanding of group decision-making processes and outcomes.
\end{abstract}




\section{Group Decision Making from an Evolutionary/Adaptationist Perspective}

There is now a fair amount of consensus among social and biological scientists that humans evolved as social creatures (Brewer \& Caporael, 2006; Caporael, Dawes, Orbell, \& Van der Kragt, 2989; Sober \& Wilson, 1998; E. O. Wilson, 2012). As Brewer and Caporael (2006, p. 143) so persuasively noted, our "weak, hairless, extended infancy" characteristics made us ill-suited for survival as lone individuals. More recently, E. O. Wilson (2012) has argued that humans are one of but a few "eusocial" species where individual members inherit traits and characteristics that support group as opposed to individual fitness. Much of the early work in evolutionary social psychology focused on mating behavior (Buss, 1989) and altruism (Trivers, 1971; Van Vugt \& Van Lange, 2006). However, evolutionary/adaptationist perspectives have recently begun to influence virtually all areas of social psychological theorizing (Schaller, Simpson, \& Kenrick, 2006), including group decision-making (Kameda \& Tindale, 2006).

In this article, we review current research on group decision-making from an evolutionary/adaptationist perspective. We attempt to show how many prominent findings in the group decision-making and problem-solving literature are consistent with fitness adaptations evolved as a function of the social nature of human existence. We first show that some basic aspects of group decision-making, such as majority and quorum-like consensus processes, are common among social animals as well as humans. In addition, coordination and motivation losses can occur with other species as well as humans. Finally, we discuss some aspects of human decision-making in groups, both positive and negative, that are consistent with a fitness adaptations perspective. Our over-arching goal is to demonstrate the 
usefulness of the evolutionary/adaptationist perspective for understanding how human groups reach consensus in a variety of decision situations.

\section{Robustness of group decision-making in the animal kingdom}

The concept of "animal group decision-making" may seem mysterious or perhaps simply metaphorical to many social scientists - other animals do not have the sophisticated language capacity of humans, nor can they deliberate over choices or cast votes. How can they make group decisions? However, recent research on animal behavior suggests group decision-making is common in the animal kingdom, and includes social insects (e.g., ants, termites, honeybees), fish, and some mammals (Conradt \& Roper, 2003, 2005; Seeley, 1995, 2010; Sumpter, Krause, James, Couzin \& Ward, 2008). More specifically, in some nonhuman social animals, specific body postures, ritualized movements or specific vocalizations indeed function as public expression of 'preferences' or 'votes' (see Conradt \& Roper, 2003). Furthermore, such voting signals can be integrated in various ways, including by a majority rule (e.g., Stewart \& Harcourt, 1994; Byrne, 2000), accumulating until an intensity threshold (quorum) is reached (e.g., Seeley \& Buhrman, 1999; Pratt, Mallon, Sumpter \& Franks, 2002), and averaging over all votes (e.g., Oldroyd, Gloag, Even, Wattanachaiyingcharoen \& Beekman, 2008). Thus, the language faculty, though undoubtedly highly beneficial, does not seem to be the prerequisite for group decision-making in general (see Kameda, Wisdom, Toyokawa and Inukai, 2012 for review).

Conradt and Roper $(2005,2009)$ proposed a useful conceptual distinction to classify animal group decision-making - combined vs. consensus decisions - which is equally applicable to humans. Combined decision-making refers to cases where animals decide individually, without requiring a consensus, but in a manner that is somehow dependent on the behavior of other group members; the aggregate results of these individual decisions 
critically affect the group as a whole. Many foraging decisions fall into this category, where foragers seek resources (e.g., nectar, prey) individually but under social influence (e.g., using social-frequency information) from other foragers. In human societies, various consumer decisions within social networks and/or on the Internet also fall into this category, as we will discuss in some detail later. Consensus decision making, on the other hand, concerns cases in which group members make decisions together with the requirement of reaching a consensus, i.e., all members abiding by the decision outcome. Moving decisions, including decisions about where and when to migrate to a new nest site, fall into this category. Some foraging decisions (e.g., cooperative hunting by both humans and non-humans) are also in this category. For human cases in particular, deliberative decision-making by committees, juries, panels, etc. are clear examples of consensus decisions (see Kameda et al., 2012 for a fuller discussion on combined vs. consensus decisions in humans as well as non-humans).

\section{Inefficiencies in group decisions-making}

In a seminal work in the field of human group behavior, Steiner (1972) provided a useful conceptual framework for studying group performance. Steiner (1972) argued that, in order to evaluate a group's productivity, some performance baseline is needed for comparison. By positing a baseline for the group's optimal level of production under the assumption of some idealized coordination/combination of member resources, we can tell how well actual groups perform compared to the optimal baseline, figuring out empirically and theoretically potential causes that determine the actual group outcomes (Kerr, 2017; Kerr $\&$ Tindale, 2004).

One normative baseline often expected for a group is given by the performance level of the group's best member (or someone leading the group intellectually; e.g., Davis, 1969; Lorge \& Solomon, 1955). Given our ordinary beliefs (e.g., “groups yield synergy”, 
"two heads are better than one"), a group should yield performance that exceeds or at least is comparable to its most competent member's solo productivity. However, previous research has consistently found that usually, groups not only fail to exceed such a baseline, but also often fall short of it (Kerr, 2017; Kerr \& Tindale, 2004). Steiner (1972) argued that such inefficiencies stem from two sources: motivation losses and coordination losses. Although initially proposed for understanding human group performance, we believe that Steiner's framework is useful for understanding group decision-making by both humans and nonhumans (Kameda \& Tindale, 2006).

\section{Motivation losses}

Motivation losses refer to members' losing motivation in a group setting. The bestknown example in social psychology is the social-loafing phenomenon, where members decrease individual inputs when their rewards are made contingent on pooled group performance (Latané, Williams, \& Harkins, 1979). Given that such a free-riding opportunity is inevitably inherent in many collective-action situations (Olson, 1965), securing members' contributions toward a common goal is a key determinant of group performance (see also Williams, Harkins \& Karau, 2003). Group decision-making is no exception in this regard. For example, economic analysis of voting behavior has identified related phenomena - problem of ignorant voters and paradox of turnout - in election (Levine \& Palfrey, 2007), where making efforts for acquiring accurate information about candidates and/or even going out to vote may seem irrational, because of the miniscule chance of being a pivotal voter in the election (Downs, 1957). In principle, such free-rider problems exist not only in election, but also in various "foraging/moving" decisions made by non-humans as well as humans. Then, how can the robust system of group decision-making, as we observe widely in nature and in our societies, evolve and/or sustain in the first place? If the logic of social dilemma (Dawes, 
1980; Ledyard, 1995) applies here, no rational individual would be expected to engage in costly information search toward a well-informed group decision, consequently degrading the "democracy" into a "mob rule."

Conventional mechanisms that have been proposed to deal with free-riding in a group include sanctions against norm-violating free-riders (e.g., Fehr \& Fischbacher, 2004), and reputation systems that promote members' cooperation (e.g., Nowak \& Sigmund, 2005). Yet, how these conventional mechanisms are applicable to group decision-making situations, especially those by non-human animals without the language faculty, remains unclear. Recently, Kameda, Tsukasaki, Berg and Hastie (2011) approached the free-rider problem from an unconventional perspective. The task situation they studied was parallel to animal consensus decision cases (Conradt \& Roper, 2005, 2009), in which 6-person groups had to reach a binding group decision to forage resources under uncertainty. Examining incentive (i.e., game) structures of the foraging task, Kameda et al. (2011) argued that many natural group-decision tasks are not necessarily social dilemmas as assumed in the previous literature (Kerr, 1983; Ledyard, 1995) where free-riding is a dominant strategy. Instead, they argued that most decision situations can be understood as a "producer-scrounger game" (Giraldeau \& Caraco, 2000; Kameda \& Nakanishi, 2002, 2003), where cooperators and defectors coexist in a stable manner at a Nash equilibrium. That is, some individuals remain cooperative in contributing to the group endeavor (e.g., engaging in costly information search, bearing voting costs) for selfish (rational) reasons, while others loaf. Neither cooperation nor freeriding is dominant in the producer-scrounger game, yielding a mixed equilibrium in a group (see Motro, 1991 and Foster, 2004, for analytic details). Kameda et al. (2011) then argued that, even if no sanctioning or reputation systems exist (Fehr \& Fischbacher, 2004; Nowak \& Sigmund, 2005), thanks to those rational cooperators, group decision-making can outperform other decision mechanisms (e.g., despotism where the best and brightest individual makes a 
decision for the group, or decision-making by isolated individuals) under uncertainty. They tested this prediction by a series of computer simulations and a behavioral experiment. Results supported their prediction, indicating that majoritarian decision-making can beat other decision mechanisms in a broad parametric range under uncertainty. These results suggest that, even when no sanctioning system exists, majoritarian group decision-making (Hastie \& Kameda, 2005) may not be as vulnerable to the free-rider problem as it has been suggested in the previous literature (Downs, 1957; Levine \& Palfrey, 2007). Kameda et al. (2011) called such superb performances of majoritarian decision-making "democracy under uncertainty" which may underlie the robust group-decision system in nature and in our societies.

\section{Coordination losses}

Coordination losses refer to inefficiencies resulting from bad coordination among members of their cognitive and/or physical inputs toward group performance (see Kerr \& Tindale, 2004 for review). Notice that the aforementioned motivation losses apply only to species living with genetically-unrelated, non-kin members (e.g., humans), where incentives for free-riding exist for each individual. This problem does not exist for eusocial insects (e.g., ants, bees) living with kin-members only, for whom cooperation for the entire group is beneficial to proliferate their own genes to the next generation. In contrast, the coordination losses are much more far-reaching across all gregarious species (e.g., Davies, Krebs \& West, 2012). Thus, as we will see below, some animals (eusocial insects in particular) have evolved built-in cognitive mechanisms to prevent coordination losses among them.

Group decisions by honey bees. In late spring or early summer, as a large hive outgrows its nest, a colony of honey bees often divides itself. The queen leaves with about $2 / 3$ of the worker bees to create a new colony, and a daughter queen stays in the old nest with 
the rest of the worker bees. The swarm leaving the colony must find a new home in a short time, which is critical to their survival. The leaving swarm, which is composed of 10,000 or so bees, typically clusters on a tree branch, while several hundred scout bees search the neighborhood for a new home. These scout bees fly out to inspect potential nest sites, and, upon returning to the colony, perform waggle dances to advertise any good sites they have discovered. The duration of the dance depends on a bee's perception of the site's quality: the better the site, the longer the dance. Other scout bees that have not flown out yet, as well as those that have stopped dancing, observe these dances and decide where to visit. In these decisions, the bees are more likely to visit and inspect the sites which have been advertised strongly by many predecessors. This process constitutes a positive feedback loop. Seeley and others (Seeley \& Buhrman, 1999; Seeley \& Visscher, 2003), who conducted a series of experiments with honeybees in natural settings, found that the bees usually can choose the best nest site. Even though none of the bees visit all the potential nest sites individually, they can aggregate partial individual information to form a collective wisdom that enables highquality decisions (Seeley, 1995, 2010).

Although the bees' performance is impressive, the puzzle still remains. How do the bees solve the problem of interdependency? The bees communicate their findings via waggle dances which are performed sequentially by scout bees. This could create statistical dependencies among decision makers, in which initial errors committed by earlier scouts can carry over and be amplified in the sequence. In this sense, the honeybee group decision making system may be susceptible to an erroneous information cascade (Bikchandani, Hirshleifer \& Welch, 1992; Kameda et al., 2012).

A recent paper has addressed this question theoretically by a computer simulation model (List, Elsholtz \& Seeley, 2009). In line with the previous empirical observations, the 
model assumes that scout bees are dependent on other bees in that they give more attention to nest sites strongly advertised by their predecessors. The bees essentially conform to a majority view in their decisions about where to visit. But, simultaneously, the model assumes that the bees are independent in assessing quality of the visited site. The duration of the scout's dance, which indexes the strength of the bee's preference for the site, is not affected by others' waggle dances but determined solely by her own perception of the site's quality. The computer simulation results showed that, when a suitable mixture of influence and independence exists, the honeybee group decision-making process works well.

Collective wisdom by humans? Honeybee nest search provides an impressive example of how animals that have only limited cognitive capacity as individuals can make "wise" decisions collectively as a swarm. It is also important to note that the "swarm intelligence" (Krause, Ruxton \& Krause, 2009; Kameda \& Hastie, 2015) in honeybees emerges not from some purposeful coordination by a central authority (e.g., the queen) but through local interactions among the bees. Interestingly, the honeybee nest-search situation seems to have similar counterparts in modern human societies, where individuals can use public information as well as private information to make a well-informed decision. Examples include information searches on the Internet when buying books or music, choosing a restaurant for dinner, deciding which hotel to stay at, and so on. Potential options are quite large in number, yet our time budget for private information search is limited. In these occasions, we often visit relevant Web sites (e.g., Amazon, Yelp) to see how others have decided. Do these social information-pooling systems on the Internet, in which individuals informed by predecessors' experiences report their own new experiences to share with others, yield collective wisdom as in the honeybee case? 
An experiment on a "cultural market" by Salganik and others focuses on this point (Salganik, Dodds \& Watts, 2006). In cultural markets, sales volumes of hit songs, books, and movies are many times greater than average. This may imply that "the best" alternatives are qualitatively different from "the rest", yet experts routinely fail to predict which cultural products will succeed. Why does this failure occur?

Intrigued by the unpredictability of cultural markets, these researchers created an experimental music market, where a total of 14,341 participants downloaded previously unknown songs under one of two conditions - the "social influence" condition or the "independent" condition. In both conditions, participants could listen to any song in which they were interested in order to directly experience the product. On top of the individual learning opportunity, participants in the "social influence" condition were provided social information about how many times each song had been downloaded by previous participants. Notice that there was a structural similarity between the social influence condition and the honey-bee nest search situation. In both situations, agents had to make choices between unfamiliar options that could differ in quality. Also, when making individual decisions, social frequency information (predecessors' behaviors) was available, in addition to the opportunities for individual information search.

The experiment revealed several interesting results. First, inequality in overall download counts among songs was much greater in the social influence condition, as compared to the independent condition in which participants could not access the socialfrequency information. Obviously, participants in the social influence condition copied predecessors' choices, which yielded a "rich get richer" outcome. Thus, the experiment replicated the robust phenomenon in cultural markets that hit songs are many times more successful than average. 
Second, the most popular songs (with the highest download frequency) in the independent condition did not necessarily correspond to the most popular ones in the social influence condition. Mapping of the songs in terms of popularity ranking between the two conditions was at most moderate - the most popular song in the independent condition never did very badly in the social influence condition, and the least popular song never did extremely well either. However, almost any other result could happen. The success of a song in the social influence condition was path-dependent and susceptible to random fluctuations, which may explain why it is difficult for even experts to predict which products will succeed in cultural markets.

Overall, how did the human performance in the experimental music market compare to the honeybee performance in nest search? A tentative answer does not seem to be favorable to humans. Honeybees mix dependence and independence in nest search. They conform to predecessors to decide which sites to visit, but assess the quality of the visited sites independently from predecessors' evaluations. This leads to the typical swarm's high performance. On the other hand, human participants in the experimental music market seemed to fail to separate the two aspects and relied too much on others' choices. Of course, the inherent subjectivity of music preferences means that the quality of experimental cultural market outcomes cannot be assessed objectively (as the nest choice decisions can). Yet, the lack of correspondence in song-popularity between the independent and the social influence conditions suggests that such subjective preferences are unstable and fragile. In this sense, the hyper susceptibility of human mass behavior to social influence is potentially problematic not only for marketers of cultural products, but also in many socio-political domains where no demonstrably correct answer exists (see Toyokawa, Kim \& Kameda, 2014 for a recent experiment that showed results similar to Salganik et al. [2006] in human combined decisions when qualities of alternatives can be assessed objectively). 


\section{Cognitive Social Sharedness}

"Social sharedness" (Kameda, Tindale, \& Davis, 2003; Tindale \& Kameda, 2000) describes the general tendency that group behavior is often overly influenced by things the group members share. The concept is well represented by the majority/plurality type processes discussed earlier in terms of group member preferences for both humans and honey bees (Kameda et al., 2012). However, there is also substantial evidence that when making decisions, groups tend to focus on information that is shared among all or most of the group members at the expense of information held uniquely by few or only one member (see Lu, Yuan, \& McLeod, 2012 for a review). This shared information effect was discovered using a hidden profile paradigm where shared information favored a less-than-optimal alternative which was often the group's collective choice (Stasser \& Titus, 1985). Later work also showed that shared information was more likely to be attended to, and was often preferred by group members relative to unshared information (Wittenbaum, Hubbel, \& Zuckerman, 1999).

Although the shared information effect leads to suboptimal decision-making when a hidden profile is present, it is unlikely that such a skewed information distribution among members (e. g., all information favoring a suboptimal alternative is shared by all members while information favoring the superior alternative is divided among the group members) is common (Brodbeck, Kerschreiter, Mojzisch, Frey, \& Schulz-Hardt, 2007). As Kameda \& Tindale (2006) argued, if group members are considered as somewhat independent information gatherers, forcussing on shared information would tend to increase group decision quality by helping to insure that only valid information informed the discussion. Brodbeck et al., noted that the shared information effect only biases group decision-making when information is distributed asymmetrically across group members. Thus, in most 
situations, focussing on shared information would lead to better group decision-making statistically.

Tindale, Smith, Thomas, Filkins, \& Sheffey (1996) discussed another type of social sharedness, called shared task representations. They defined a shared task representation as "any task/situation relevant concept, norm, perspective, or cognitive process that is shared by most or all of the group members" (Tindale et al., 1996, p. 84). "Task/situation relevant" means that the representation must have implications for the choice alternatives involved, and the degree to which a shared representation affects group decision processes and outcomes will vary as a function of its relevance. Its influence will also vary by the degree to which it is shared among the group members - the greater the degree of sharedness (the more members who share it), the greater its influence. If no shared task representation exists, or if multiple conflicting representations are present, groups will tend to follow a symmetric majority/plurality process. However, when a shared task representation does exist, the group decision process will tend to become asymmetric in favor of alternatives that fit within or are supported by the representation. For example, Laughlin and Ellis (1986) found that a single minority member with the correct solution to a math problem could convince the incorrect group members to change by demonstrating the correct solution fit with the laws of mathematics. The laws of mathematics form a shared task representation for a math problem. Smith, Dykema-Engblade, Walker, Niven, and McGough (2000) found minority group members who were against the death penalty could be persuasive in changing death penalty attitudes by using arguments drawn from the group's shared religious background.

Tindale et al. (1996) showed how shared task representations can lead to biased group decisions, but once again, such situations are probably rare. It is more likely that shared background knowledge that is task relevant leads to better decisions by groups. One of the 
key components of Laughlin and Ellis' (1986) definition of a task which has a “demonstrably correct solution" is a shared system of axioms or beliefs that provide the context in which a solution's "correctness" can be demonstrated. Thus, non-majority factions favoring a demonstrably correct solution can sway incorrect majorities to accept the minority position (see also Levine, 2017). This is how Laughlin (2011) explains the typical finding that groups are better problem-solvers than individuals. However, even when groups share the appropriate background knowledge to demonstrate a solution as correct, some degree of preference sharing is typically necessary to insure groups reach optimal decisions (Laughlin, 1980). This is evidenced by findings that show "truth-supported wins" (at least two correct solvers are necessary in a group for the group to solve the problem correctly) tends to provide a better fit to group problem-solving data than does "truth wins" (a single correct solver is sufficient for group correctness). It seems some minimal amount of social support for "truth" in addition to an appropriate shared task representation is necessary for groups to perform optimally. Recent research has shown that the additional correct member increases the likelihood that correct members will argue convincingly for the correctness of their position (Aramovich \& Larson, 2013). Thus, social sharedness may be adaptive at many levels and a convergence across levels leads to greater confidence in the group's collective choice.

\section{Ingroup Favoritism, Group Enhancement/Protection Norm and Ethical Decision Making}

Decades of research has shown that when group membership is salient, group members act in ways that favor their group over others (Abrams, 2015; Hogg \& Abrams, 1988). Social Identity/Self-Categorization theory argues that group identification leads directly to ingroup favoritism and other behaviors that differentiate ones group from others (Hogg \& Abrams, 1988; Turner et al., 1987). Work on the role of groups in evolutionary adaptation of the species argues that living and hunting in groups had survival implications 
and being rejected by the group could lead to starvation and death (Brewer \& Caporael, 2006; Hogg, Abrams, \& Brewer, 2017; Levine \& Kerr, 2007). Additional simulation studies (Choi $\&$ Bowles, 2007) have found that societies with a substantial number of members who are "Parochial altruists" (those who sacrifice for the ingroup and shun or aggress against outgroup members) tend to be stable while societies with mainly non-exclusive altruists die off over time (see also Arrow, 2007). More recent work has begun to isolate the physiological and neurological correlates of these effects and has shown that oxytocin helps to regulate responses to both ingroup and outgroup members (De Dreu, Greer, Handgraaf, Shalvi, et al., 2010).

There is also a large body of research showing that groups are far more likely than individuals to choose defection in prisoner's dilemma game (Wildschut, Pinter, Vevea, Insko, \& Schopler, 2003; Morgan \& Tindale, 2002). Tindale, Morgan, Stawiski et al. (2006) found such tendencies even when defection was not the dominant response in the game. They also found that both majority and minority factions favoring defection were considerably more influential in the groups' discussions than were comparable factions favoring cooperation. Tindale, Talbot, \& Martinez (2013) have argued that decision alternatives that either enhance or protect the group become normative in such decision settings and are much easier to defend during group discussion. They refer to this tendency as the "group enhancement/protection norm" and assume it is derives from similar mechanisms associated with ingroup favoritism (Hogg, Abrams, \& Brewer, 2017; Tajfel, 1971). More recently, Tindale, Shi, Kluwe, and Winget (2015) hypothesized that the group enhancement/protection norm would tend to lead groups to be less ethical than individuals when making decisions that have implications for the group's welfare. Using both ethical dilemma problems and a business simulation case, they found that groups were more likely than individuals to choose the unethical option in the ethical dilemma and generally favored less ethical options in the 
business simulation. For the business simulation case, majorities favoring the less ethical options were more influential than comparable majorities favoring the more ethical options. These results are similar to findings on group member tolerance for leader transgressions (Abrams, Ramsley de Mora, \& Travaglino, 2013).

\section{Summary and Conclusions}

In this article, we attempted to demonstrate the usefulness of an evolutionary/adaptationist approach to understanding group decision-making processes and outcomes. Given that humans lived in groups throughout their existence, it should not be surprising that they evolved to solve problems associated with group life (Kameda, Van Vugt, \& Tindale, 2015). For both accuracy and acceptance, it appears that human groups evolved formal and informal decision-making procedures (e.g., quorum rules in consensus decisions) and built-in psycho-physiological algorithms (e.g., social influence in combined decisions) that took into account the collective preferences of the group. We also attempted to show that humans are not unique among species in terms of using group decision processes to make choices relevant to the group. Future studies comparing human groups to nonhuman groups may allow us to further understand how human cognition both aids and interferes with collective decision processes and performance. Further, we feel that the evolutionary/adaptationist approach both helps to explain group behavior generally but also helps to integrate theory and research on intra and intergroup processes, a major goal of Group Processes and Intergroup Relations. We hope that going forward, research with other eusocial species can both inform and enrich our understanding of human group decisionmaking and that interdisciplinary exchanges continue and become more frequent. 


\section{References}

Abrams, D. (2015). Social identity and intergroup relations. In In M. Mikulincer \& P. R. Shaver (Eds.), J. Dovidio \& J. Simpson (Assoc. Eds.), APA Handbook of personality and social psychology: Volume 2, Group processes (pp. 203 - 228). Washington, DC: American Psychological Association.

Abrams, D., Randsley de Moura, G., \& Travaglino, G. (2013). A double standard when group members behave badly: Transgression credit to ingroup leaders. Journal of Personality and Social Psychology. doi:10.1037/a0033600

Aramovich, N. P., \& Larson, J. R. (2013). Strategic demonstration of problem solutions by groups: The effects of member preferences, confidence, and learning goals. Organizational Behavior and Human Decision Processes, 122, 36-52. doi.org/10.1016/j.obhdp.2013.04.001

Arrow, H. (2007). The sharp end of altruism. Science, 318, 581-582. DOI: 10.1126/science. 1150316

Bikhchandani, S., Hirshleifer, D., \& Welch, I. (1992). A theory of fads, fashion, custom, and cultural change as informational cascades. Journal of Political Economy, 100, 9921026. doi.org/10.1086/261849

Brodbeck, F. C., Kerschreiter, R., Mojzisch, A., Frey, D, \& Schulz-Hardt, S. (2007). Group decision making under conditions of distributed knowledge: The information asymmetries model. Academy of Management Journal, 32, 459-479.

\section{doi:10.5465/AMR.2007.24351441}

Buss, D. M. (1989). Sex differences in human mate preferences: Evolutionary hypotheses tested in 37 cultures. Behavioral and Brain Sciences, 12, 1-49. DOI: 
Byrne, R. W. (2000). How monkeys find their way: leadership, coordination, and cognitive maps of African baboons. In S. Boinski \& P. Garber (Eds.), On the move (pp. 491518). Chicago, IL: University of Chicago Press.

Caporael, L. R., \& Brewer, M. B. (2006). An evolutionary perspective on social identity: Revisiting groups. In M. Schaller, J. A. Simpson, \& D. T. Kenrick (Eds.) Evolution and social psychology (pp. 143 - 161). New York: Psychology Press.

Caporael, L. R., Dawes, R. M., Orbell, J. M., \& van de Kragt, A. J. C. (1989). Selfishness examined: Cooperation in the absence of egoistic incentives. Behavioral and Brain Sciences, 12, 683-739. DOI: https://doi.org/10.1017/S0140525X00025292

Choi, J., \& Bowles, S. (2007). The coevolution of parochial altruism and war. Science, 318, 636-640. DOI: $10.1126 /$ science. 1144237

Conradt, L., \& List, C. (Eds.) (2009). Theme issue: group decision making in humans and animals. Philosophical Transactions of the Royal Society B, 364, 719-852.

Conradt, L., \& Roper, T.J. (2003). Group decision-making in animals. Nature, 421, 155-158. doi:10.1038/nature01294

Conradt, L., \& Roper, T.J. (2005). Consensus decision making in animals. Trends in Ecology and Evolution, 20, 449-456. doi.org/10.1016/j.tree.2005.05.008

Davies, N.B., Krebs, J.R., \& West, S.A. (2012). An introduction to behavioural ecology (4 ${ }^{\text {th }}$ ed.). Oxford: Wiley-Blackwell.

Davis, J. H. (1969). Group performance. Reading, MA: Addison-Wesley.

Dawes, R.M. (1980). Social dilemmas. Annual Review of Psychology, 31, 169-193. DOI: 10.1146/annurev.ps.31.020180.001125 
De Dreu, C. K. W., Greer, L. L., Handgraaf, M. J. J., Shalvi, S., Van Kleef, G. A., Baas, M., Ten Velden, F. S., Van Dijk, E., \& Feith, S. W. W. (2010). The neuropeptide Oxytocin regulates parochial altruism in intergroup conflict among humans. Science, 328, 1408-1411. DOI: $10.1126 /$ science. 1189047

Downs, A. (1957). An economic theory of democracy. New York: Harper and Row.

Fehr, E., \& Fischbacher, U. (2004). Social norms and human cooperation. Trends in Cognitive Sciences, 8, 185-190. doi.org/10.1016/j.tics.2004.02.007

Foster, K.R. (2004). Diminishing returns in social evolution: the not-so-tragic commons. Journal of Evolutionary Biology, 17, 1058-1072. DOI: 10.1111/j.14209101.2004.00747.x

Gilardeau, L-A., \& Caraco, T. (2000). Social foraging theory. Princeton, NJ: Princeton University Press.

Hastie, R., \& Kameda, T. (2005). The robust beauty of majority rules in group decisions. Psychological Review, 112, 494-508. doi.org/10.1037/0033-295X.112.2.494

Hogg, M. A., Abrams, D., \& Brewer, M. B. (2017). Social identity: The role of self in group processes and intergroup relations. Group Processes and Intergroup Relations, 20(5).

Kameda, T., \& Hastie, R. (2015). Herd behavior: Its biological, neural, cognitive and social underpinnings. In R. Scott \& S. Kosslyn (Eds.), Emerging trends in the social and behavioral sciences. Hoboken, NJ: John Wiley and Sons.

Kameda, T., \& Nakanishi, D. (2002). Cost-benefit analysis of social/cultural learning in a non-stationary uncertain environment: An evolutionary simulation and an experiment 
with human subjects. Evolution and Human Behavior, 23, 373-393.

http://dx.doi.org/10.1016/S1090-5138(02)00101-0

Kameda, T., \& Nakanishi, D. (2003). Does social/cultural learning increase human adaptability? Rogers' question revisited. Evolution and Human Behavior, 24, 242-260. doi.org/10.1016/S1090-5138(03)00015-1

Kameda, T., \& Tindale, R. S. (2006). Groups as adaptive devices: Human docility and group aggregation mechanisms in evolutionary context. In M. Schaller, J. Simpson, \& D. Kenrick (Eds.), Evolution and Social Psychology. (pp.317-341). New York: Psychology Press

Kameda, T., Tsukasaki, T., Hastie, R., \& Berg, N. (2011). Democracy under uncertainty: The wisdom of crowds and the free-rider problem in group decision making. Psychological Review, 118, 76-96. doi.org/10.1037/a0020699

Kameda, T., Van Vugt, M., \& Tindale, R. S. (2015). Groups. In V. Zeigler-Hill, L. L. M. Welling, \& T. K. Shackelford (Eds.) Evolutionary perspectives on social psychology (pp. 243 -254). New York: Springer.

Kameda, T., Wisdom, T., Toyowaka, W., \& Inukai, K. (2012). Is consensus-seeking unique to humans? A selective review of animal group decision-making and its implications for (human) social psychology. Group Processes and Intergroup Relations, 15, 673689. DOI: https://doi.org/10.1177/1368430212451863

Kerr, N.L. (1983). Motivation losses in small groups: A social dilemma analysis. Journal of Personality and Social Psychology, 45, 819-828. doi.org/10.1037/0022-3514.45.4.819

Kerr, N.L. (2017). The most neglected moderator in group research. Group Processes and Intergroup Relations, 20 (5). 
Kerr, N.L., \& Tindale, R.S. (2004). Group performance and decision making. Annual Review of Psychology, 55, 623-655. DOI: 10.1146/annurev.psych.55.090902.142009

Krause, J., Ruxton, G.D., \& Krause, S. (2009). Swarm intelligence in animals and humans. Trends in Ecology and Evolution, 25, 28-34. doi.org/10.1016/j.tree.2009.06.016

Latané, B., Williams, K., \& Harkins, S. (1979). Many hands make light the work: The causes and consequences of social loafing. Journal of Personality and Social Psychology, 37, 822-832. doi.org/10.1037/0022-3514.37.6.822

Laughlin, P. R. (1980). Social combination processes of cooperative, problem-solving groups on verbal intellective tasks. In M. Fishbein (Ed.), Progress in social psychology (Vol. 1, pp. 127-155). Hillsdale, NJ: Lawrence Erlbaum.

Laughlin, P. R. (2011). Group problem solving. Princeton, NJ: Princeton University Press.

Laughlin, P. R., \& Ellis, A. L. (1986). Demonstrability and social combination processes on mathematical intellective tasks. Journal of Experimental Social Psychology, 22, 177189. doi.org/10.1016/0022-1031(86)90022-3

Ledyard, J.O. (1995). Public goods: A survey of experimental research. In J. Kagel \& A. Roth (Eds.), Handbook of Experimental Economics (pp.111-194). Princeton: Princeton University Press.

Levine, J. M. (2017). Factional conflict in groups: How majorities and minorities relate to one another. Group Processes and Intergroup Relations, 20(5).

Levine, J. M., \& Kerr, N. L. (2007). Inclusion and exclusion: Implications for group processes. In A. E. Kruglanski \& E. T. Higgins (Eds.), Social psychology: Handbook of basic principles (2nd ed., pp. 759-784). New York: Guilford. 
Levine, D.K., \& Palfrey, T.R. (2007). The paradox of voter participation? A laboratory study. American Political Science Review, 101, 143-158. DOI: 10.1017.S0003055407070013

List, C., Elsholtz, C., \& Seeley, T.D. (2009). Independence and interdependence in collective decision making: an agent-based model. Philosophical Transactions of the Royal Society $B, \mathbf{3 6 4}, 755-762$.

Lorge, I., \& Solomon, H. (1955). Two models of group behavior in the solution of eurekatype problems. Psychmetrica, 20, 139-148. DOI: 10.1007/BF02288986

Lu, L., Yuan, Y., \& McLeod, P. L. (2012). Twenty-five years of hidden profile studies: A meta-analysis. Personality and Social Psychology Review. 16, 54-75. doi.org/10.1177/1088868311417243

Morgan, P. M., \& Tindale, R. S. (2002). Group vs. individual performance in mixed motive situations: Exploring an inconsistency. Organizational Behavior and Human Decision Processes, 87, 44-65. doi.org/10.1006/obhd.2001.2952

Motro, U. (1991). Co-operation and defection: Playing the Field and the ESS. Journal of Theoretical Biology, 151, 145-154. doi.org/10.1016/S0022-5193(05)80358-3

Nowak, M.A. \& Sigmund, K. (2005). Evolution of indirect reciprocity. Nature, 437, 12911298. doi: $10.1038 / 31225$

Oldroyd, B.P., Gloag, R.S., Even, N., Wattanachaiyingcharoen, W., \& Beekman, M. (2008). Nest site selection in the open-nesting honeybee Apis florea. Behavioral Ecology and Sociobiology, 62, 1643-1653. DOI: 10.1007/s00265-008-0593-5

Olson, M. (1965). The logic of collective action: Public goods and the theory of groups. Cambridge, MA: Harvard University Press 
Pratt, S.C., Mallon, E.B., Sumpter, D.J.T., \& Franks, N.R. (2002). Quorum sensing, recruitment, and collective decision-making during colony emigration by the ant Leptothorax albipennis. Behavioral Ecology and Sociobiology, 52, 117-127. DOI: $10.1007 / \mathrm{s} 00265-002-0487-\mathrm{x}$

Salganik, M.J., Dodds, P.S., \& Watts, D. (2006). Experimental study of inequality and cultural market. Science, 311, 854-856. DOI: 10.1126/science.1121066

Seeley, T.D. (1995). The wisdom of the hive: The social physiology of honey bee colonies. Cambridge, MA: Harvard University Press.

Seeley, T.D. (2010). Honeybee democracy. Princeton, NJ: Princeton University Press.

Seeley, T.D., \& Buhrman, S.C. (1999). Group decision making in swarms of honey bees. Behavioral Ecology and Sociobiology, 45, 19-31. DOI: 10.1007/s002650050536

Seeley, T.D., \& Visscher, P.K. (2003) Choosing a home: how the scouts in a honey bee swarm perceive the completion of their decision making. Behavioral Ecology and Sociobiology, 54, 511-520. DOI: 10.1007/s00265-003-0664-6

Sober, E., \& Wilson, D. S. (1998). Unto others: The evolution and psychology of unselfish behavior. Cambridge, MA: Harvard University Press.

Stasser, G., \& Titus, W. (1985). Pooling of unshared information in group decision making: Biased information sampling during discussion. Journal of Personality and Social Psychology, 48, 1467-1478. doi.org/10.1037/0022-3514.48.6.1467

Stewart, K. J., \& Harcourt, A. H. (1994). Gorilla vocalisations during rest periods—signals of impending departure. Behaviour, 130, 29-40. DOI: $\underline{10.1163 / 156853994 X 00127}$ 
Sumpter, D.J.T., Krause, J., James, R., Couzin I.D., \& Ward, A.J.W. (2008). Consensus decision making by fish. Current Biology, 18, 1773-1777. doi.org/10.1016/j.cub.2008.09.064

Tindale, R. S., Morgan, P., Stawiski, S., Dykema-Engblade, A., Meisenhelder, H., Wittkowski, E., \& Jacobs, E. (2006). Further explorations of the individual-group discontinuity effect. Paper presented at the First Annual INGRoup Conference, Pittsburgh, PA.

Tindale, R. S., Shi, Z., Kluwe, K., \& Winget, J. (2015). Are groups less ethical than individuals? Poster presented at the International Convention for Psychological Science, Amsterdam, NE.

Tindale, R. S., Smith, C. M., Thomas, L. S., Filkins, J., \& Sheffey, S. (1996). Shared representations and asymmetric social influence processes in small groups. In E. Witte, \& J. H. Davis (Eds.), Understanding group behavior: Consensual action by small groups (Vol. 1, pp. 81-103). Mahwah, NJ: Lawrence Erlbaum.

Tindale, R. S., Talbot, M., \& Martinez, R. (2013). Group decision making. In J. M. Levine (Ed.) Group processes (pp. 165 - 194). New York: Psychology Press.

Toyokawa, W., Kim, H., \& Kameda, T. (2014). Human collective intelligence under dual exploration-exploitation dilemmas. PLoS ONE, 9(4): e95789. doi.org/10.1371/journal.pone.0095789

Trivers, R. L. (1971). The evolution of reciprocal altruism. The Quarterly Review of biology, 46, 35-57. DOI: 10.1086/406755

Turner, J. C., Hogg, M. A., Oakes, P. J., Reicher, S. D., \& Wetherell, M. S. (1987). Rediscovering the social group: A self-categorization theory. Oxford, UK: Blackwell. 
Van Vugt, M., \& Van Lange, P. A. M. (2006). The altruism puzzle: Psychological adaptations for prosocial behavior. In M. Schaller, J. A. Simpson, \& D. T. Kenrick (Eds.) Evolution and social psychology (pp. 237 - 262). New York: Psychology Press.

Wildschut, T., Pinter, B., Vevea, J. L., Insko, C. A., \& Schopler, C. A. (2003). Beyond the group mind: A quantitative review of the interindividual-intergroup discontinuity effect. Psychological Bulletin, 129, 698-722. doi.org/10.1037/0033-2909.129.5.698

Williams, K. D., Harkins, S. G., \& Karau, S. J. (2003). Social performance. In M. A. Hogg \& J. Cooper (Eds.), Sage handbook of social psychology (pp. 327-346). London: Sage.

Wilson, E. O. (2012). The social conquest of earth. New York: W. W. Norton \& Company.

Wittenbaum, G. M., Hubbell, A. P., \& Zuckerman, C. (1999). Mutual enhancement: Toward an understanding of collective preference for shared information. Journal of Personality and Social Psychology, 77, 967-978. doi.org/10.1037/0022-3514.77.5.967 